\title{
Theory of Square-Wave Voltammetry of Two-Electron Reduction with the Adsorption of Intermediate
}

\author{
Milivoj Lovrić and Šebojka Komorsky-Lovrić \\ Department of Marine and Environmental Research, Ruder Bošković Institute, 10000 Zagreb, Croatia \\ Correspondence should be addressed to Milivoj Lovrić, mlovric@irb.hr
}

Received 9 December 2011; Revised 13 January 2012; Accepted 13 January 2012

Academic Editor: Sheng S. Zhang

Copyright (c) 2012 M. Lovrić and Š. Komorsky-Lovrić. This is an open access article distributed under the Creative Commons Attribution License, which permits unrestricted use, distribution, and reproduction in any medium, provided the original work is properly cited.

\begin{abstract}
Thermodynamically unstable intermediate of fast and reversible two-electron electrode reaction can be stabilized by the adsorption to the electrode surface. In square-wave voltammetry of this reaction mechanism, the split response may appear if the electrode surface is not completely covered by the adsorbed intermediate. The dependence of the difference between the net peak potentials of the prepeak and postpeak on the square-wave frequency is analyzed theoretically. This relationship can be used for the estimation of adsorption constant.
\end{abstract}

\section{Introduction}

In polarography and voltammetry of electrode reactions consisting of two-electron transfers, the responses depend on the stability of intermediates [1-6]. In the case of fast and reversible electroreduction, two waves or peaks appear if the standard potential of the second electron transfer is two hundred millivolts or more lower than the standard potential of the first electron transfer $[2,3]$. For the difference in standard potentials higher than $-0.1 \mathrm{~V}$, the response is a single wave or peak [6]. Thermodynamically unstable intermediate can be kinetically stabilized if the second charge transfer is slow $[1,3,4]$. Furthermore, the intermediate can be stabilized by the adsorption to the electrode surface [711]. This phenomenon was observed in electroreduction of hydrogen $[8,9]$, chloropyridines [12], and paraquet [13], in electrooxidation of bismuth [7], aluminum [14], and methanol [15], in the passivation of cobalt electrode [16], and in the anodic evolution of oxygen [17]. The theory of two-electron reaction complicated by the adsorption of intermediate is developed for pulse and differential pulse polarography [18-23] and for impedance measurements [24-26], and in this paper the theory is extended to squarewave voltammetry [27-29]. For this technique there are theories for two-step simple and catalytic surface reactions in which all electroactive species are strongly adsorbed to the electrode surface [30-33].

\section{The Model}

The following reaction mechanism is analyzed:

$$
\begin{gathered}
\mathrm{Ox}^{(n+2)+}+e^{-} \rightleftarrows \operatorname{Int}^{(n+1)+}, \\
\mathrm{Int}^{(n+1)+}+e^{-} \rightleftarrows \operatorname{Red}^{n+}, \\
\mathrm{Int}^{(n+1)+} \rightleftarrows\left(\operatorname{Int}^{(n+1)+}\right)_{\text {ads }}
\end{gathered}
$$

where $n=0,1,2$, or more. It is assumed that only the reactant $\mathrm{Ox}^{(n+2)+}$ is initially present in the solution, that the mass transfer occurs through the stationary, planar, semi-infinite diffusion, that both electron transfers are fast and reversible, that all diffusion coefficients are equal, that the adsorption can be described by Langmuir isotherm, and that there are no interactions between molecules in the adsorbed monolayer. The system of differential equations for three electroactive species:

$$
\frac{\partial c_{Y}}{\partial t}=D \frac{\partial^{2} c_{Y}}{\partial x^{2}}
$$


(where $Y=\mathrm{Ox}^{(n+2)+}$, $\operatorname{Int}^{(n+1)+}$, and $\operatorname{Red}^{n+}$ ) is solved for the initial and boundary conditions:

$$
\begin{aligned}
& t=0, \quad x \geq 0: c_{\mathrm{Ox}}=c_{\mathrm{Ox}}^{*}, \quad c_{\text {Int }}=0, \quad c_{\text {Red }}=0, \quad \Gamma_{\text {Int }}=0, \\
& x=0: D\left(\frac{\partial c_{\mathrm{Ox}}}{\partial x}\right)_{x=0}=-\frac{I_{1}}{F S} \\
& D\left(\frac{\partial c_{\text {Int }}}{\partial x}\right)_{x=0}=\frac{d \Gamma_{\text {Int }}}{d t}+\frac{I_{1}-I_{2}}{F S} \\
& D\left(\frac{\partial c_{\mathrm{Red}}}{\partial x}\right)_{x=0}=\frac{I_{2}}{F S} \\
& I=I_{1}+I_{2} \text {, } \\
& \left(c_{\text {Ox }}\right)_{x=0}=\left(c_{\text {Int }}\right)_{x=0} \exp \left(\varphi_{1}\right) \\
& \left(c_{\text {Int }}\right)_{x=0}=\left(c_{\text {Red }}\right)_{x=0} \exp \left(\varphi_{2}\right), \\
& \varphi_{1}=\frac{F}{R T}\left(E-E_{1}^{0}\right) \\
& \varphi_{2}=\frac{F}{R T}\left(E-E_{2}^{0}\right) \\
& \beta\left(c_{\text {Int }}\right)_{x=0}=\frac{\Gamma_{\text {Int }}}{\Gamma_{\max }-\Gamma_{\text {Int }}} .
\end{aligned}
$$$$
t>0, \quad x \longrightarrow \infty: c_{\mathrm{Ox}} \longrightarrow c_{\mathrm{Ox}}^{*}, \quad c_{\mathrm{Int}} \longrightarrow 0, \quad c_{\mathrm{Red}} \longrightarrow 0
$$

The meanings of all symbols are given in Table 1. Equation (4) is transformed into the system of integral equations and solved by the numerical method of Olmstead and Nicholson [34]. A dimensionless current $\Phi=I\left(F c_{\mathrm{Ox}}^{*}\right)^{-1}(D f)^{-1 / 2}$ is calculated as a function of electrode potential. The solutions are reported in the appendix.

\section{Results and Discussion}

Theoretical square-wave voltammogram of simple, reversible two-electron reaction depends on the difference in standard potentials of two charge transfers $\left(E_{2}^{0}-E_{1}^{0}\right)$, on square-wave

\begin{tabular}{|c|c|}
\hline$\beta$ & Adsorption constant \\
\hline$c_{\mathrm{Ox}}, c_{\mathrm{Int}}, c_{\mathrm{Red}}$ & $\begin{array}{l}\text { Concentrations of the reactant, intermediate and } \\
\text { the product }\end{array}$ \\
\hline$c_{\mathrm{Ox}}^{*}$ & $\begin{array}{l}\text { Concentrations of the reactant in the bulk of } \\
\text { solution }\end{array}$ \\
\hline$D$ & Common diffusion coefficient \\
\hline$d E$ & Square-wave potential increment \\
\hline$E$ & Electrode potential \\
\hline$E_{1}^{0}, E_{2}^{0}$ & $\begin{array}{l}\text { Standard potentials of the first and the second } \\
\text { electron transfers }\end{array}$ \\
\hline$E_{\mathrm{sw}}$ & Square-wave amplitude \\
\hline$E_{p}$ & Peak potential \\
\hline$E_{p, 1}, E_{p, 2}$ & Peak potentials of the prepeak and postpeak \\
\hline$E_{p, f}, E_{p, b}$ & $\begin{array}{l}\text { Peak potentials of the forward and backward } \\
\text { components }\end{array}$ \\
\hline$E_{\text {st }}$ & Starting potential \\
\hline$F$ & Faraday constant \\
\hline$f$ & Square-wave frequency \\
\hline$\varphi$ & Dimensionless potential difference \\
\hline$\Phi$ & Dimensionless current \\
\hline$\Phi_{f}, \Phi_{b}$ & $\begin{array}{l}\text { Dimensionless currents of the forward and } \\
\text { backward components }\end{array}$ \\
\hline$-\Delta \Phi_{p}$ & Dimensionless net peak current \\
\hline$\Phi_{p, f}, \Phi_{p, b}$ & $\begin{array}{l}\text { Dimensionless peak currents of the forward and } \\
\text { back wardcomponents }\end{array}$ \\
\hline$\Gamma_{\text {Int }}$ & Surface concentration of adsorbed intermediate \\
\hline$\Gamma_{\max }$ & $\begin{array}{l}\text { Maximum surface concentration of adsorbed } \\
\text { intermediate }\end{array}$ \\
\hline$R$ & Gas constant \\
\hline$S$ & Electrode surface area \\
\hline$t$ & Time \\
\hline$T$ & Temperature \\
\hline$\theta$ & Surface coverage \\
\hline$x$ & Distance perpendicular to the electrode surface \\
\hline
\end{tabular}
amplitude $\left(E_{S W}\right)$, and on potential increment $(d E)$. If $E_{1}^{0}=$ $E_{2}^{0}, E_{\mathrm{SW}}=50 \mathrm{mV}$, and $d E=-5 \mathrm{mV}$, the voltammogram is a single peak with the maximum at the standard potential and the dimensionless net peak current $-\Delta \Phi_{p}=1.6835$. The characteristics of the forward, reductive and the backward, oxidative components are the following: $\Phi_{p, f}=-1.0483$, $E_{p, f}=E_{1}^{0}, \Phi_{p, b}=0.6352$, and $E_{p, b}=E_{1}^{0}$. Under the influence of adsorption of intermediate, the voltammogram depends
TABle 1: Meanings of symbols.

on two additional parameters: the dimensionless reactant concentration $\left(\beta c_{\mathrm{Ox}}^{*}\right)$ and the dimensionless adsorption constant $\left(\beta \Gamma_{\max } \sqrt{f / D}\right)$. Note that the adsorption constant of Henry isotherm is equal to the product $\beta \Gamma_{\max }$.

Figure 1 shows the influence of the product $\beta c_{\mathrm{Ox}}^{*}$. If this product is smaller than 25 , the response is split into two peaks with the maxima at $0.075 \mathrm{~V}$ and $-0.070 \mathrm{~V}$ versus $E_{1}^{0}$. The net peak currents in Figure 1(a) are 0.88 and 1.36, respectively. These values change from 0.90 and 1.51 , for $\beta c_{\mathrm{Ox}}^{*}=$ 0.1 , to 0.86 and 1.17 for $\beta c_{\mathrm{Ox}}^{*}=25$. The splitting appears because the adsorption of intermediate facilitates the transfer of the first electron but requires an additional energy for the reduction of adsorbed intermediate $[18,20,22]$. So, the peaks 1 and 2 in Figure 1(a) are the prepeak and postpeak, respectively. The condition for the split response is that the electrode surface is not fully covered by the adsorbed monolayer. Assuming that $\beta=10^{8} \mathrm{~cm}^{3} / \mathrm{mol}$, as it was observed 


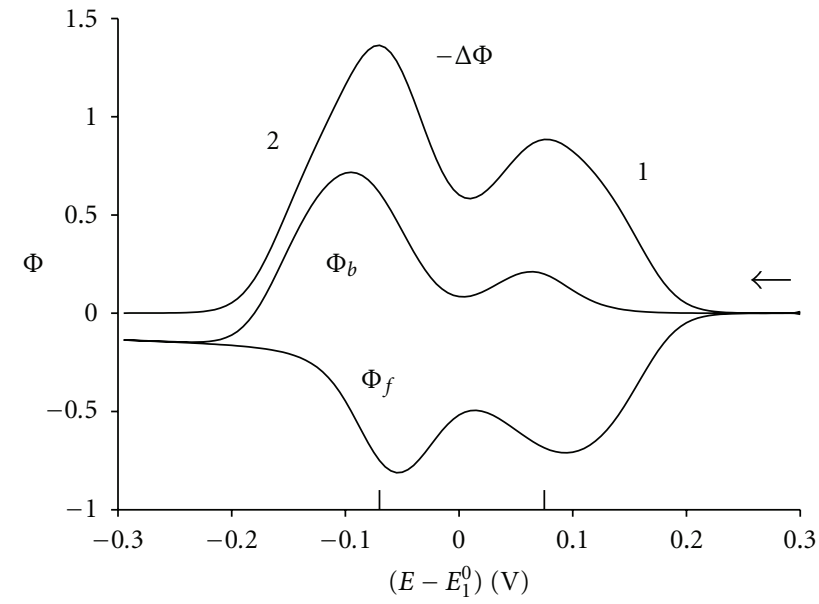

(a)

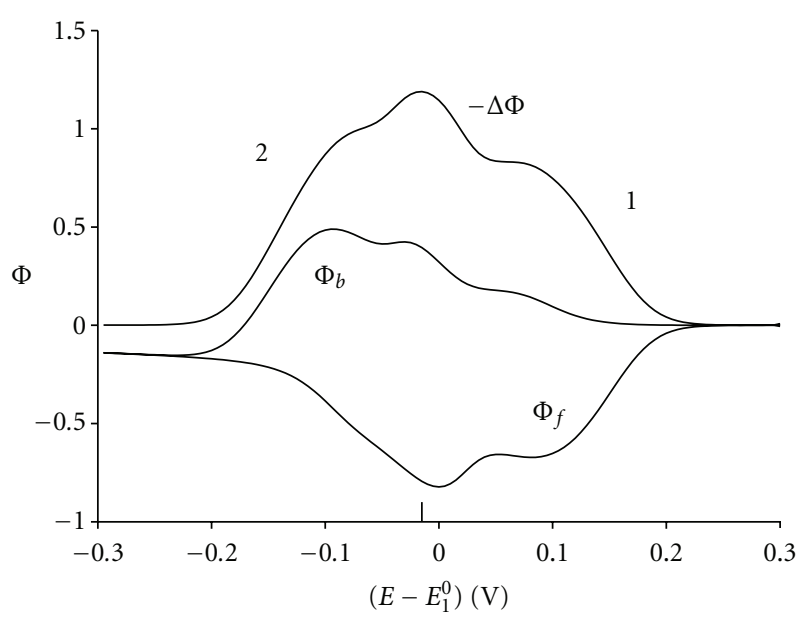

(b)

FIGURE 1: Square-wave voltammetry (SWV) of electrode reactions (1)-(3). $E_{2}^{0}=E_{1}^{0}, E_{\mathrm{SW}}=50 \mathrm{mV}, d E=-5 \mathrm{mV}, E_{\mathrm{st}}=0.3 \mathrm{~V}$ versus $E_{1}^{0}$, $\beta \Gamma_{\max } \sqrt{(f / D)}=100$, and $\beta c_{\mathrm{Ox}}^{*}=10$ (a) and 40 (b). The net peak potentials are marked by the short vertical lines above the abscissa.

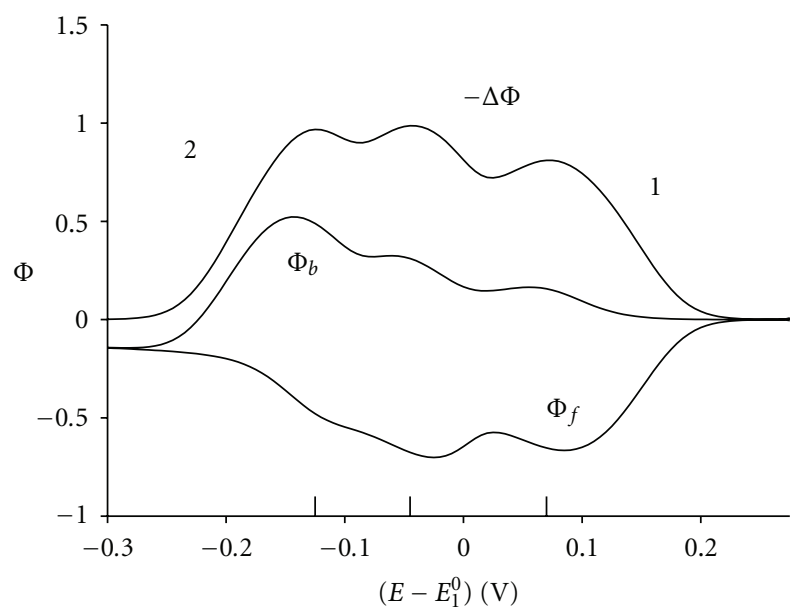

Figure 2: SWV of the reactions (1)-(3). $E_{2}^{0}-E_{1}^{0}=-0.050 \mathrm{~V}$ and $\beta c_{\mathrm{Ox}}^{*}=40$. All other parameters are as in Figure 1.

in the anion-induced adsorption of some metal ions [35$37]$, this condition is satisfied for $c_{\mathrm{Ox}}^{*}<2.5 \times 10^{-4} \mathrm{~mol} / \mathrm{L}$. At higher concentrations the main peak develops, as can be seen in Figure 1(b). Its net peak potential is $-0.015 \mathrm{~V}$ versus $E_{1}^{0}$. The minimum in the forward component and the maximum in the backward component that correspond to the main peak appear at $E_{1}^{0}$ and $-0.030 \mathrm{~V}$ versus $E_{1}^{0}$, respectively. If $\beta c_{\mathrm{Ox}}^{*}=150$, the maximum of the main peak appears at $E_{1}^{0}$, and the potentials of minimum and maximum of the forward and backward components are $0.005 \mathrm{~V}$ and $-0.005 \mathrm{~V}$ versus $E_{1}^{0}$, respectively.

The separation between net peak potentials of the split response is independent of the reactant concentration but depends on the square-wave amplitude. If $E_{\mathrm{SW}}=$ $20 \mathrm{mV}, E_{p, 1}-E_{p, 2}=175 \mathrm{mV}$, and if $E_{S W}=70 \mathrm{mV}$,

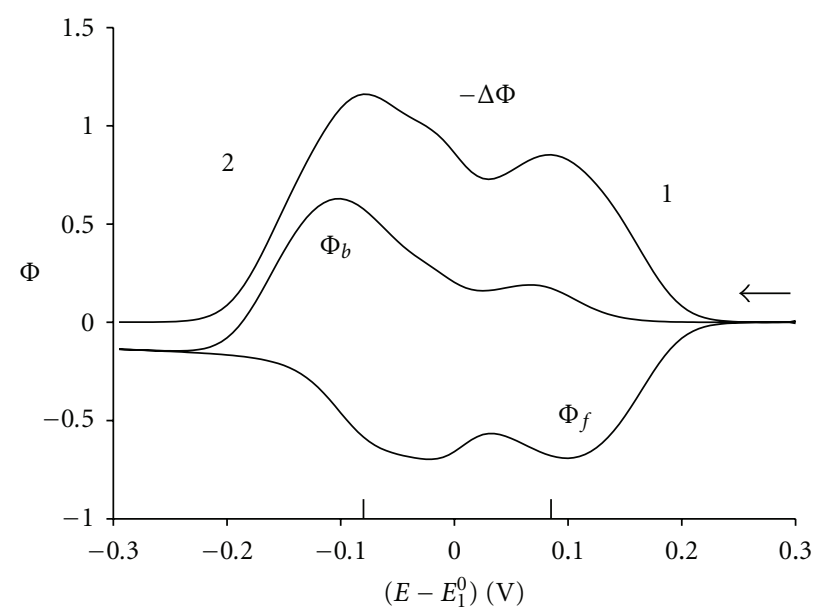

FIGURE 3: SWV of the reactions (1)-(3). $\beta c_{\mathrm{Ox}}^{*}=40$ and $\beta \Gamma_{\max } \sqrt{(f / D)}=150$. All other parameters are as in Figure 1.

$E_{p, 1}-E_{p, 2}=110 \mathrm{mV}$. For this reason all analyses in this work are performed with the amplitude of $50 \mathrm{mV}$.

Figure 2 shows the voltammogram calculated for $E_{2}^{0}-$ $E_{1}^{0}=-0.050 \mathrm{~V}$. All other conditions are as in Figure 1(b). It can be noted that the prepeak and the postpeak are more pronounced than in Figure 1(b). The difference in their net peak potentials is $195 \mathrm{mV}$, and if $E_{2}^{0}-E_{1}^{0}=-0.100 \mathrm{~V}$, this difference increases to $250 \mathrm{mV}$. Oppositely, if $E_{2}^{0}-E_{1}^{0} \geq$ $0.050 \mathrm{~V}$, the prepeak and postpeak disappear under the conditions of Figure 1(b), which means that they are less separated than for $E_{1}^{0}=E_{2}^{0}$. These results suggest that the difference $E_{p, 1}-E_{p, 2}$ is an indicator of thermodynamic property of the reaction mechanism (1)-(3).

The influence of adsorption constant is shown in Figure 3, which is to be compared with Figure 1(b). If neither $\beta$ nor the reactant concentration are changed, the parameter 


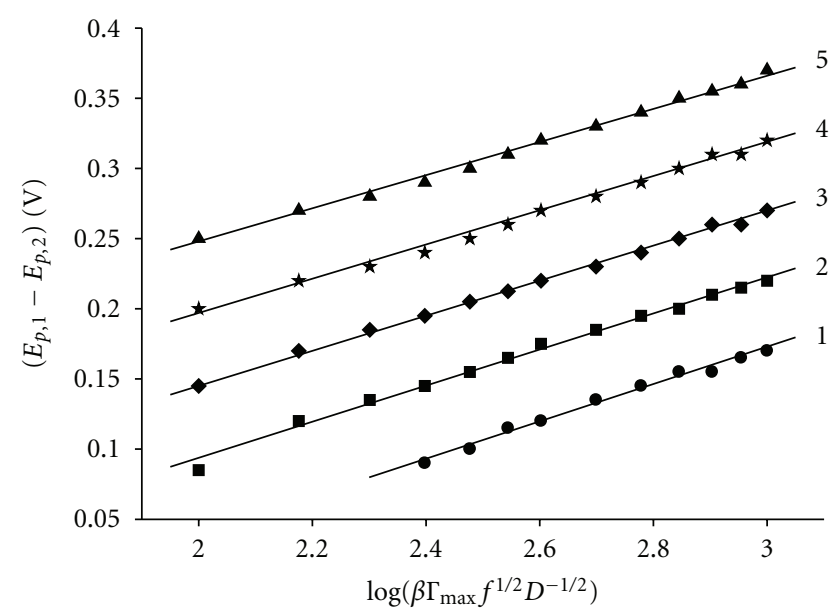

Figure 4: Dependence of the difference in net peak potentials of the prepeak and postpeak on the logarithm of dimensionless adsorption parameter (the symbols). $\beta c_{\mathrm{Ox}}^{*}=10$ and $\left(E_{2}^{0}-E_{1}^{0}\right) / \mathrm{V}=$ 0.100 (1), 0.050 (2), 0.000 (3), -0.050 (4), and -0.100 (5). The lines are linear approximations. All other parameters are as in Figure 1.

$\beta \Gamma_{\max } \sqrt{f / D}$ can be augmented by increasing either $\Gamma_{\max }$ or frequency. In the first case the surface coverage is diminished, which explains why in Figure 3 the main peak is much smaller than in Figure 1(b). Also, the difference $E_{p, 1}-E_{p, 2}$ increases to $165 \mathrm{mV}$, compared to $145 \mathrm{mV}$ in Figure 1(a). The same can be achieved by the variation of frequency, which can be changed between $10 \mathrm{~Hz}$ and $2000 \mathrm{~Hz}$.

The relationships between the difference $E_{p, 1}-E_{p, 2}$ and the logarithm of parameter $\beta \Gamma_{\max } \sqrt{f / D}$ are shown in Figure 4 for various standard potentials and for the unsaturated electrode surface $\left(\beta c_{\mathrm{Ox}}^{*}=10\right)$. All these functions are straight lines with the slopes and intercepts that depend on the difference in standard potentials. Figure 5 shows that these dependences are also linear: slope $=0.075 \times\left(E_{2}^{0}-E_{1}^{0}\right)+$ $0.1255 \mathrm{~V}$ and intercept $=-1.19 \times\left(E_{2}^{0}-E_{1}^{0}\right)-0.107 \mathrm{~V}$. So, the relationships in Figure 4 can be described by the following formulae:

$$
\begin{aligned}
E_{p, 1}-E_{p, 2}= & {\left[0.075 \times\left(E_{2}^{0}-E_{1}^{0}\right)+0.1255\right] } \\
& \times \log \left(\beta \Gamma_{\max } \sqrt{f / D}\right) \\
& -1.19 \times\left(E_{2}^{0}-E_{1}^{0}\right)-0.107 \mathrm{~V} .
\end{aligned}
$$

However, as the difference $E_{2}^{0}-E_{1}^{0}$ is generally unknown, the average values of the slope and the intercept can be used for the estimation of adsorption constant:

$$
\begin{aligned}
E_{p, 1}-E_{p, 2}= & (0.1255 \pm 0.0075) \\
& \times\left[\log \left(\frac{\beta \Gamma_{\max }}{\sqrt{D}}\right)+\frac{1}{2} \log f\right] \\
& -0.107 \pm 0.119 \mathrm{~V} .
\end{aligned}
$$

For instance, if the difference $E_{p, 1}-E_{p, 2}=0.220 \mathrm{~V}$ is measured at $f=144 \mathrm{~Hz}$, the parameter $\beta \Gamma_{\max } / \sqrt{D}$ can be cal- culated using (17): $\log \left(\beta \Gamma_{\max } / \sqrt{D}\right)=1.5 \pm 1.0$. The precision of this estimation is obviously very modest.

Finally, our calculations show that the maximal currents of prepeak and postpeak depend linearly on the square-root of frequency and on $f^{0.583}$, respectively.

\section{Conclusion}

These results show that the adsorption of thermodynamically unstable intermediate can cause the splitting of square-wave voltammogram of two-electron electrode reaction. If $\beta c_{\mathrm{Ox}}^{*}<$ 25 , the difference between net peak potentials of the prepeak and postpeak is independent of reactant concentration and depends on the difference in standard potentials of two electron transfers and on the logarithm of the dimensionless adsorption parameter $\beta \Gamma_{\max } \sqrt{f / D}$ as defined by (16). This equation applies for reversible charge transfers, equal diffusion coefficients, $E_{\mathrm{SW}}=50 \mathrm{mV}, d E=-5 \mathrm{mV},-0.1 \mathrm{~V} \leq$ $E_{2}^{0}-E_{1}^{0}<0.1 \mathrm{~V}$, and $\beta \Gamma_{\max } \sqrt{(f / D)} \geq 100$. If $E_{2}^{0}-E_{1}^{0}=0.1 \mathrm{~V}$, the splitting occurs for $\beta \Gamma_{\max } \sqrt{(f / D)}>200$.

\section{Appendix}

By the substitution $\psi=c_{\mathrm{Ox}}+c_{\text {Int }}+c_{\text {Red }}$, the system of differential equations (4) is reduced to the single differential equation

$$
\frac{\partial \psi}{\partial t}=D \frac{\partial^{2} \psi}{\partial x^{2}}
$$

with the following initial and boundary conditions:

$$
\begin{gathered}
t=0, x \geq 0: \psi=c_{\mathrm{Ox}}^{*}, \Gamma_{\text {Int }}=0, \\
t>0, x \rightarrow \infty: \psi \rightarrow c_{\mathrm{OX}}^{*}, \\
x=0: D\left(\frac{\partial \psi}{\partial x}\right)_{x=0}=\frac{d \Gamma_{\text {Int }}}{d t}, \\
\psi_{x=0}=\left(c_{\text {Int }}\right)_{x=0}\left[\exp \left(\varphi_{1}\right)+1+\exp \left(-\varphi_{2}\right)\right],
\end{gathered}
$$

$$
\frac{\beta \psi_{x=0}}{1+\exp \left(\varphi_{1}\right)+\exp \left(-\varphi_{2}\right)}=\frac{\Gamma_{\text {Int }}}{\Gamma_{\max }-\Gamma_{\text {Int }}} .
$$

Using Laplace transforms, (A.1) is transformed into integral equation

$$
\psi_{x=0}=c_{\mathrm{Ox}}^{*}-(D \pi)^{-1 / 2} \frac{\partial}{\partial t} \int_{0}^{t} \frac{\Gamma_{\mathrm{Int}} d \tau}{\sqrt{t-\tau}} .
$$

The time $t$ is divided into $m$ increments $(t=m d)$, and it is assumed that within each increment the function $\Gamma_{\text {Int }}$ can be replaced by the average value $\Gamma_{\text {Int, } j}$ [34]. Furthermore, it is defined that each square-wave half-period is divided into 25 


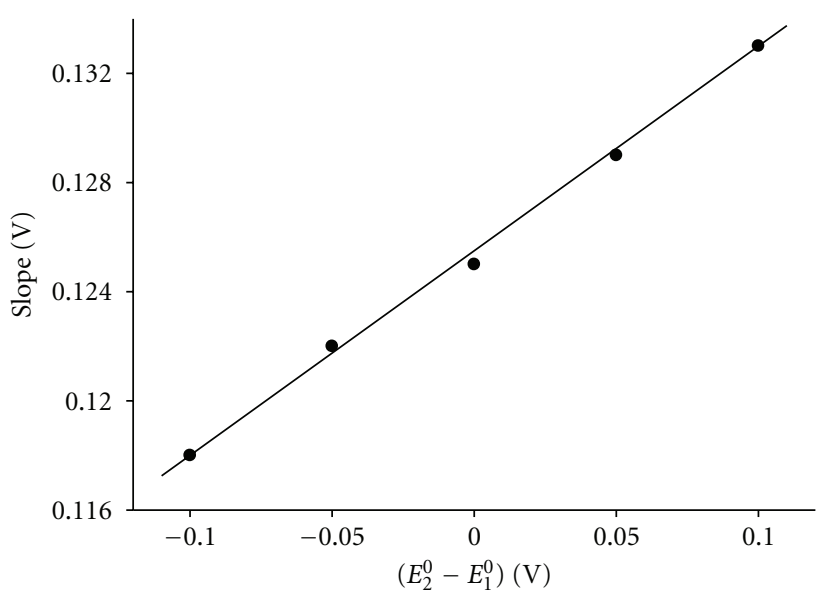

(a)

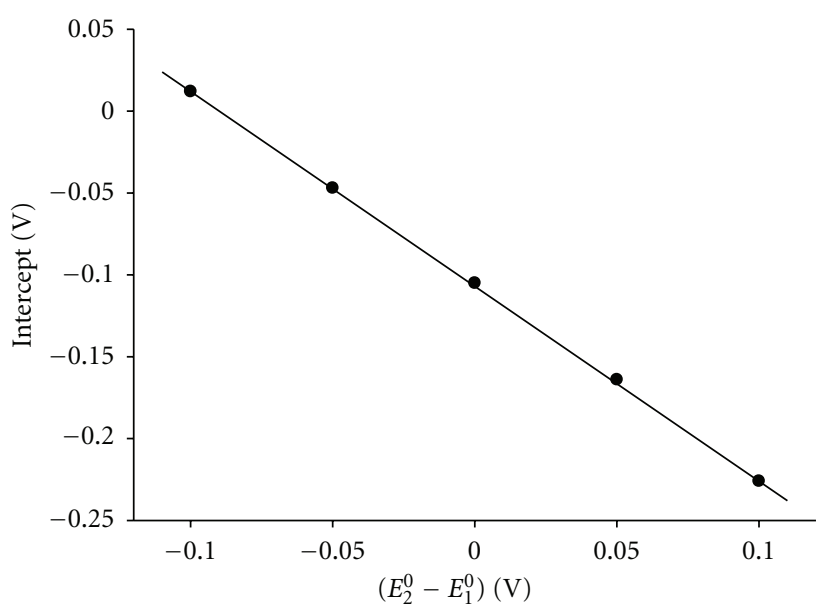

(b)

Figure 5: Dependence of the slopes (a) and the intercepts (b) of straight lines shown in Figure 4 on the difference in standard potentials of the second and the first electron transfers (the symbols). The lines are linear approximations.

time increments: $d=(50 f)^{-1}$. In this way the solution of (A.7) is obtained:

$\psi_{x=0, m}=c_{\mathrm{Ox}}^{*}-\frac{10 \sqrt{2 f}}{\sqrt{D \pi}}\left(\Gamma_{\mathrm{Int}, m}+\sum_{j=1}^{m-1} \Gamma_{\mathrm{Int}, j}\left(S_{m-j+1}-S_{m-j}\right)\right)$,

where $m=1,2,3, \ldots$ and $S_{k}=\sqrt{k}-\sqrt{k-1}$. Equation (A.8) is introduced into (A.6) to obtain the solution for the surface coverage $\theta_{\text {Int }, m}=\Gamma_{\text {Int }, m} / \Gamma_{\text {max }}$ :

$$
\begin{gathered}
\theta_{\text {Int }, m}=-\frac{z_{1, m}}{2}-\frac{\sqrt{z_{1, m}^{2}-4 z_{2, m}}}{2}, \\
z_{1, m}=-1-\frac{\beta c_{\mathrm{Ox}}^{*}+\left[1+\exp \left(\varphi_{1, m}\right)+\exp \left(-\varphi_{2, m}\right)\right]}{10 \sqrt{2} / \sqrt{\pi} \cdot(\beta \sqrt{f} / \sqrt{D}) \Gamma_{\max }} \\
+\sum_{j=1}^{m-1} \theta_{j}\left(S_{m-j+1}-S_{m-j}\right), \\
z_{2, m}=\frac{\beta c_{\mathrm{Ox}}^{*}}{10 \sqrt{2} / \sqrt{\pi} \cdot(\beta \sqrt{f} / \sqrt{D}) \Gamma_{\max }} \\
-\sum_{j=1}^{m-1} \theta_{j}\left(S_{m-j+1}-S_{m-j}\right), \\
\varphi_{l, m}=\frac{F}{R T}\left(E_{m}-E_{l}^{0}\right)
\end{gathered}
$$

(where $l=1$ and 2). The surface concentrations of electroactive species are defined by (11), (12), (15), and (A.9):

$$
\left(c_{\text {Int }}\right)_{x=0, m}=\frac{1}{\beta} \cdot \frac{\theta_{\text {Int }, m}}{1-\theta_{\text {Int }, m}},
$$

$$
\begin{gathered}
\left(c_{\mathrm{Ox}}\right)_{x=0, m}=\frac{\exp \left(\varphi_{1, m}\right)}{\beta} \cdot \frac{\theta_{\mathrm{Int}, m}}{1-\theta_{\mathrm{Int}, m}}, \\
\left(c_{\text {Red }}\right)_{x=0, m}=\frac{\exp \left(-\varphi_{2, m}\right)}{\beta} \cdot \frac{\theta_{\mathrm{Int}, m}}{1-\theta_{\mathrm{Int}, m}} .
\end{gathered}
$$

The currents $I_{1}$ and $I_{2}$ are determined by solving (4) for $Y=$ $\mathrm{Ox}^{(n+2)+}$ and $Y=\operatorname{Red}^{n+}$, respectively:

$$
\begin{gathered}
\frac{I_{1}}{F S \sqrt{D}}=-\frac{c_{\mathrm{Ox}}^{*}}{\sqrt{\pi t}}+\frac{\partial}{\partial t} \int_{0}^{t} \frac{\left(c_{\mathrm{Ox}}\right)_{x=0}}{\sqrt{\pi(t-\tau)}} d \tau, \\
\frac{I_{2}}{F S \sqrt{D}}=-\frac{\partial}{\partial t} \int_{0}^{t} \frac{\left(c_{\mathrm{Red}}\right)_{x=0}}{\sqrt{\pi(t-\tau)}} d \tau .
\end{gathered}
$$

Using (A.14) and (A.15) and the numerical method described previously, the solution for the dimensionless current $\Phi_{m}=\left(I_{1, m}+I_{2, m}\right)\left(F S c_{\mathrm{Ox}}^{*}\right)^{-1}(D f)^{-1 / 2}$ is obtained:

$$
\begin{aligned}
\Phi_{1, m}=-\frac{5 \sqrt{2}}{\sqrt{m \pi}}+\frac{10 \sqrt{2}}{\sqrt{\pi}}\left[\frac{\left(c_{\mathrm{Ox}}\right)_{x=0, m}}{c_{\mathrm{Ox}}^{*}}\right. \\
\left.+\sum_{j=1}^{m-1} \frac{\left(c_{\mathrm{Ox}}\right)_{x=0, j}}{c_{\mathrm{Ox}}^{*}}\left(S_{m-j+1}-S_{m-j}\right)\right],
\end{aligned}
$$

$$
\begin{aligned}
\Phi_{2, m}=-\frac{10 \sqrt{2}}{\sqrt{\pi}}\left[\frac{\left(c_{\mathrm{Red}}\right)_{x=0, m}}{c_{\mathrm{Ox}}^{*}}\right. \\
\left.+\sum_{j=1}^{m-1} \frac{\left(c_{\mathrm{Red}}\right)_{x=0, j}}{c_{\mathrm{Ox}}^{*}}\left(S_{m-j+1}-S_{m-j}\right)\right] .
\end{aligned}
$$

The forward and backward components of square-wave voltammogram and their difference $\left(-\Delta \Phi=-\left(\Phi_{f}-\Phi_{b}\right)\right)$ are calculated. 


\section{References}

[1] D. H. Evans, "One-electron and two-electron transfers in electrochemistry and homogeneous solution reactions," Chemical Reviews, vol. 108, no. 7, pp. 2113-2144, 2008.

[2] D. S. Polcyn and I. Shain, "Multistep charge transfers in stationary electrode polarography," Analytical Chemistry, vol. 38, no. 3, pp. 370-375, 1966.

[3] J. Galvez, R. Saura, A. Molina, and T. Fuente, "Current-potential curves with an EE mechanism," Journal of Electroanalytical Chemistry, vol. 139, no. 1, pp. 15-36, 1982.

[4] S. Treimer, A. Tang, and D. C. Johnson, "A consideration of the application of Koutecký-Levich plots in the diagnoses of charge-transfer mechanisms at rotated disk electrodes," Electroanalysis, vol. 14, no. 3, pp. 165-171, 2002.

[5] S. R. Belding, R. Baron, E. J. F. Dickinson, and R. G. Compton, "Modeling diffusion effects for a stepwise two-electron reduction process at a microelectrode: study of the reduction of para-quaterphenyl in tetrahydrofuran and inference of fast comproportionation of the dianion with the neutral parent molecule," Journal of Physical Chemistry C, vol. 113, no. 36, pp. 16042-16050, 2009.

[6] A. Molina, C. Serna, M. López-Tenés, and M. M. Moreno, "Theoretical background for the behavior of molecules containing multiple interacting or noninteracting redox centers in any multipotential step technique and cyclic voltammetry," Journal of Electroanalytical Chemistry, vol. 576, no. 1, pp. 9-19, 2005.

[7] O. A. Kopistko, "The galvanostatic double-pulse method in the study of the kinetics of stepwise electrode processes involving the adsorption of intermediates," Journal of Electroanalytical Chemistry, vol. 224, no. 1-2, pp. 67-94, 1987.

[8] D. A. Harrington and B. E. Conway, "ac impedance of faradaic reactions involving electrosorbed intermediates-I. Kinetic theory," Electrochimica Acta, vol. 32, no. 12, pp. 1703-1712, 1987.

[9] P. Gu, L. Bai, L. Gao, R. Brousseau, and B. E. Conway, "Problems in the determination of adsorption behaviour of intermediates in faradaic reactions: distinction between double layer and adsorption capacitance of electrocatalysts determined from fast potential relaxation transients," Electrochimica Acta, vol. 37, no. 12, pp. 2145-2154, 1992.

[10] S. Rouquette-Sanchez and G. Picard, "Electrochemical oxidation of a metal involving two successive charge transfer steps with adsorbed intermediate species-I. Theoretical expressions for the steady state current-potential curves," Electrochimica Acta, vol. 38, no. 4, pp. 487-493, 1993.

[11] A. Sadkowski, "On some dynamic peculiarities of the charge transfer with adsorption and attractive interactions," Electrochimica Acta, vol. 49, no. 14, pp. 2259-2269, 2004.

[12] S. Kashti and E. Kirowa-Eisner, "The effects of adsorption conformation of intermediates on the kinetic parameters of an electrode process mechanism of the electroreduction of chloropyridines on the dme," Journal of Electroanalytical Chemistry, vol. 103, no. 1, pp. 119-135, 1979.

[13] B. S. Garg and N. Pardeep, "Investigations on adsorption of paraquet radical cations on gold electrodes by voltammetry coupled with laser Raman spectroscopy," Proceedings of the Indian Academy of Sciences-Chemical Sciences, vol. 105, no. 4-5, pp. 287-294, 1993.

[14] L. Péter, J. Arai, and H. Akahoshi, "Impedance of a reaction involving two adsorbed intermediates: aluminum dissolution in non-aqueous lithium imide solutions," Journal of Electroanalytical Chemistry, vol. 482, no. 2, pp. 125-138, 2000.
[15] K. A. Assiongbon and D. Roy, "Electro-oxidation of methanol on gold in alkaline media: adsorption characteristics of reaction intermediates studied using time resolved electro-chemical impedance and surface plasmon resonance techniques," Surface Science, vol. 594, no. 1-3, pp. 99-119, 2005.

[16] I. M. Novoselsky and N. R. Menglisheva, "Investigation of kinetics of initial stages of cobalt electrode passivation by voltamperometric method. Experiment and theory of consecutive surface electro-chemical reaction complicated by chemical steps of dissolution intermediates," Electrochimica Acta, vol. 29, no. 1, pp. 21-27, 1984.

[17] J. C. K. Ho, G. T. Filho, R. Simpraga, and B. E. Conway, "Structure influence on electrocatalysis and adsorption of intermediates in the anodic $\mathrm{O}_{2}$ evolution at dimorphic $\alpha$ - and $\beta$ $\mathrm{PbO}_{2}$," Journal of Electroanalytical Chemistry, vol. 366, no. 1-2, pp. 147-162, 1994.

[18] M. Lovrić, "The theory of the ee mechanism with adsorption of the intermediate," Journal of Electroanalytical Chemistry, vol. 153, no. 1-2, pp. 1-27, 1983.

[19] M. Lovrić, "Capacitive currents in pulse polarography for the case of the reversible E $\downarrow \mathrm{E}$ mechanism," Journal of Electroanalytical Chemistry, vol. 175, no. 1-2, pp. 33-52, 1984.

[20] J. Galvez, M. L. Alcaraz, and S. M. Park, "Theory of the ee mechanism with adsorption of the intermediate at an electrode expanding with any power law or at a DME (expanding sphere electrode model)," Journal of Electroanalytical Chemistry, vol. 247, no. 1-2, pp. 119-133, 1988.

[21] J. Galvez, M. L. Alcaraz, and S.-M. Park, "Errata," Journal of Electroanalytical Chemistry, vol. 260, no. 1, p. 248, 1989.

[22] J. Galvez, M. L. Alcaraz, and S. M. Park, "Theory of the EE mechanism with adsorption of the intermediate in normal pulse polarography," Journal of Electroanalytical Chemistry, vol. 266, no. 1, pp. 1-9, 1989.

[23] M. L. Alcaraz and J. Galvez, "Study of the EE mechanism with adsorption of the intermediate at spherical and planar electrodes following Langmuir isotherm," Collection Czechoslovak Chemical Communications, vol. 56, no. 1, pp. 60-67, 1991.

[24] D. A. Harrington, "Theory of electrochemical impedance of surface reactions: second-harmonic and large-amplitude response," Canadian Journal of Chemistry, vol. 75, no. 11, pp. 1508-1517, 1997.

[25] J. P. Diard, B. Le Gorrec, and C. Montella, "Non-linear impedance for a two-step electrode reaction with an intermediate adsorbed species," Electrochimica Acta, vol. 42, no. 7, pp. 1053-1072, 1997.

[26] K. Darowicki, "The fixed state in impedance measurements of a two-step electrode reaction proceeding with accompanying adsorption of an intermediate product," Electrochimica Acta, vol. 42, no. 7, pp. 1073-1079, 1997.

[27] M. S. Krause Jr. and L. Ramaley, "Analytical application of square wave voltammetry," Analytical Chemistry, vol. 41, no. 11, pp. 1365-1369, 1969.

[28] J. H. Christie, J. A. Turner, and R. A. Osteryoung, "Square wave voltammetry at the dropping mercury electrode: theory," Aanalytical Chemistry, vol. 49, no. 13, pp. 1899-1903, 1977.

[29] J. J. O'Dea, J. Osteryoung, and R. A. Osteryoung, “Theory of square wave voltammetry for kinetic systems," Analytical Chemistry, vol. 53, no. 4, pp. 695-701, 1981.

[30] R. Gulaboski and Lj. Mihajlov, "Catalytic mechanism in successive two-step protein-film voltammetry - theoretical study in square-wave voltammetry," Biophysical Chemistry, vol. 155, no. 1, pp. 1-9, 2011. 
[31] R. Gulaboski, "Surface ECE mechanism in protein film voltammetry-a theoretical study under conditions of square-wave voltammetry," Journal of Solid State Electrochemistry, vol. 13, no. 7, pp. 1015-1024, 2009.

[32] V. Mirčeski and R. Gulaboski, "A theoretical and experimental study of a two-step quasireversible surface redox reaction by square-wave voltammetry," Croatica Chemica Acta, vol. 76, no. 1, pp. 37-48, 2003.

[33] J. J. O’Dea and J. G. Osteryoung, “Square wave voltammetry for two-step surface reductions," Analytical Chemistry, vol. 69, no. 4, pp. 650-658, 1997.

[34] M. L. Olmstead and R. S. Nicholson, "A method based on polynomial approximations for numerical solution of volterra integral equations," Journal of Electroanalytical Chemistry, vol. 16, no. 2, pp. 145-151, 1968.

[35] M. Zelić and M. Lovrić, "The influence of electrolyte concentration on the parameters of the Frumkin isotherm in the $\mathrm{Cd}^{2+}-\mathrm{I}^{-}$system," Journal of Electroanalytical Chemistry, vol. 541, pp. 67-76, 2003.

[36] M. Lovrić and Š. Komorsky-Lovrić, "Adsorption of $\mathrm{PbBr}_{2}$ complex on mercury electrodes," Langmuir, vol. 11, no. 5, pp. 1784-1790, 1995.

[37] M. Zelić and M. Lovrić, "Bromide induced adsorption of lead ions on mercury electrodes," Electrochimica Acta, vol. 35, no. 11-12, pp. 1701-1706, 1990. 


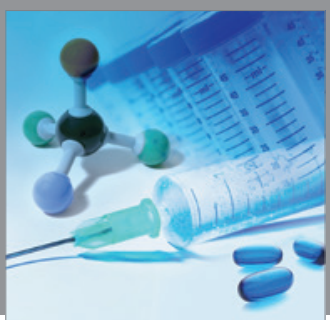

International Journal of

Medicinal Chemistry

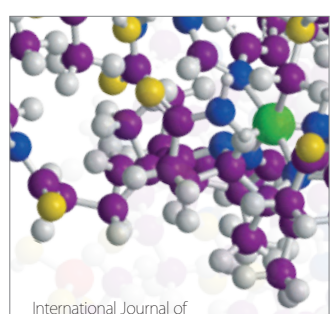

Carbohydrate Chemistry

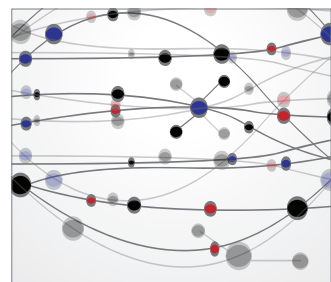

The Scientific World Journal
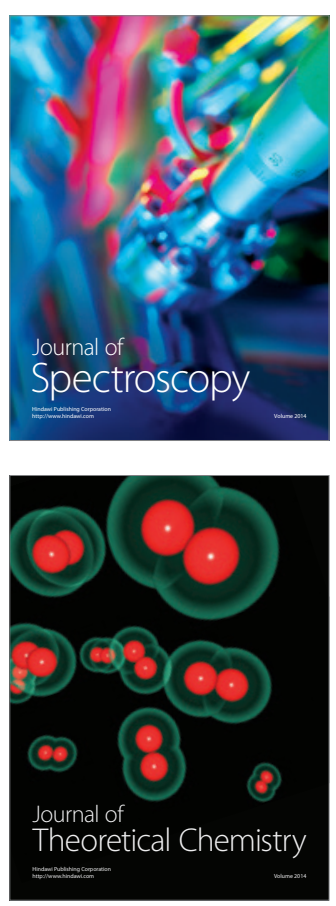
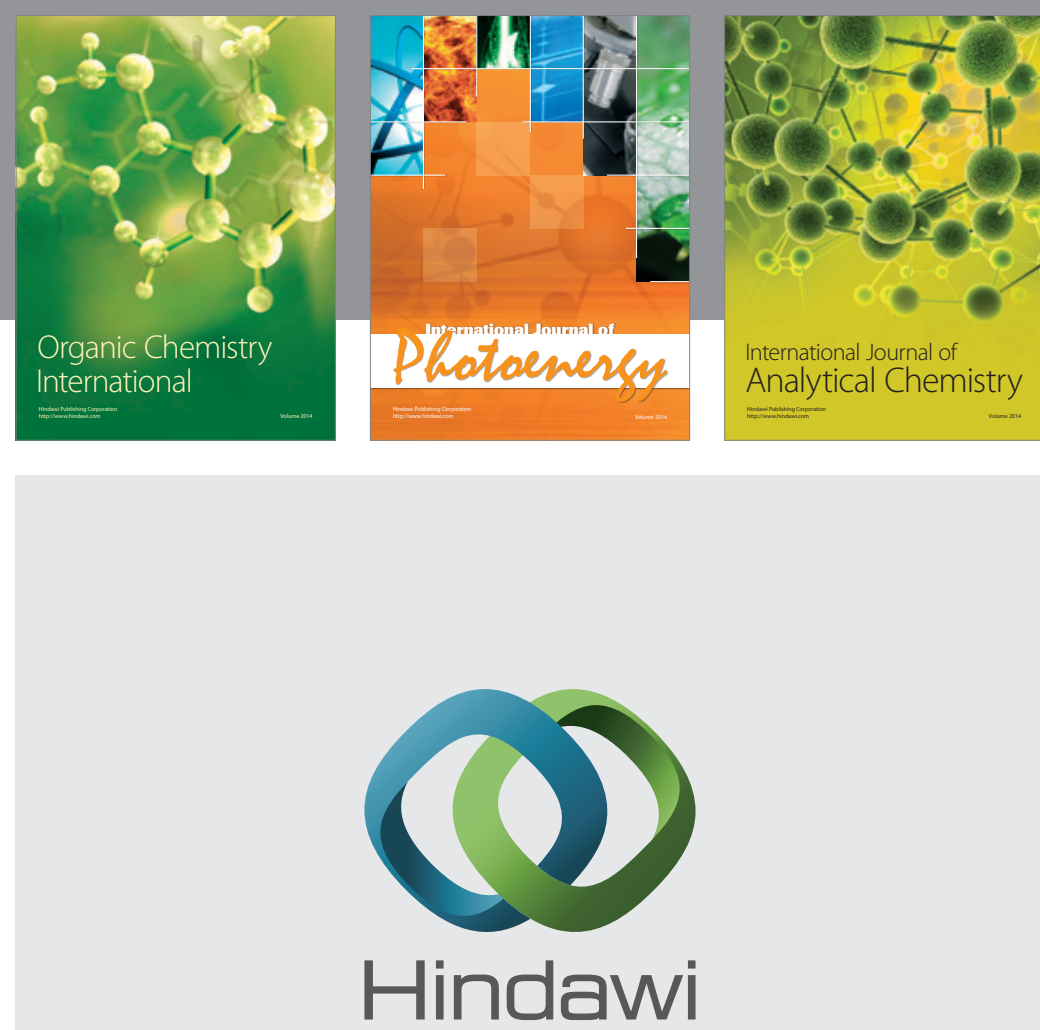

Submit your manuscripts at

http://www.hindawi.com
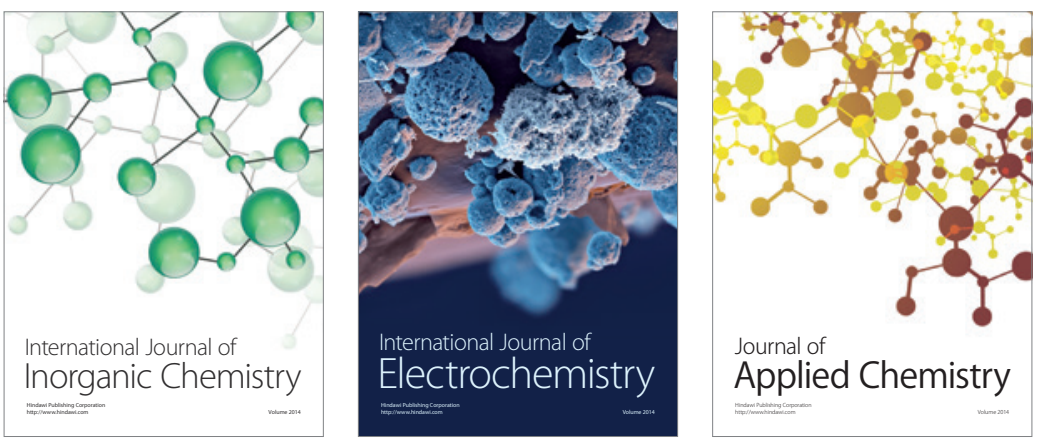

Journal of

Applied Chemistry
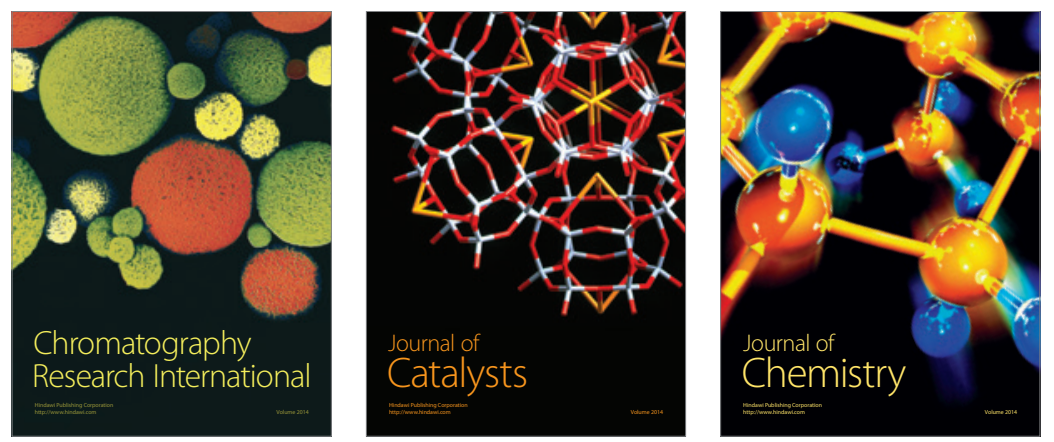
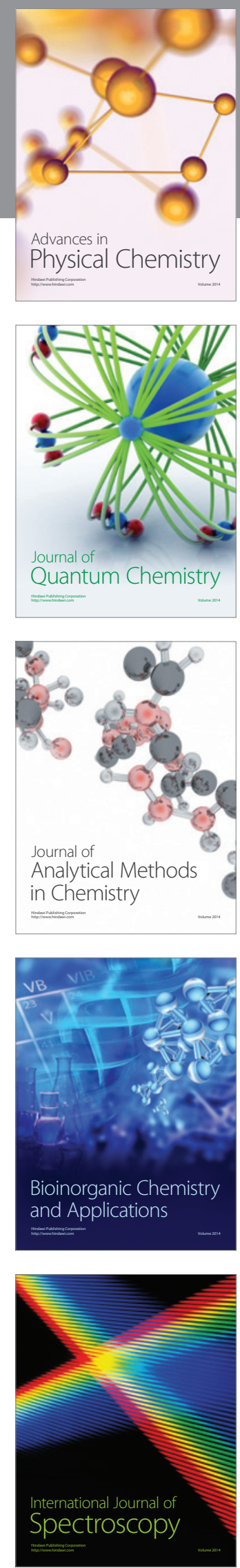